\title{
Synthesis of Poly(4-vinyl-1,4-butyrolactone-co-cyanoethylene)
}

\author{
Takeo SHIMIDZu, ${ }^{*}$ Masakazu YoshiKawA, Masayuki HasegawA, \\ and Hiroshi FuJIMOTO \\ Department of Hydrocarbon Chemistry, Faculty of Engineering, \\ Kyoto University, Kyoto 606, Japan.
}

(Received January 9, 1979)

\begin{abstract}
Copolymerization of 4-vinyl-1,4-butyrolactone (1) and cyanoethylene (2) initiated by $2,2^{\prime}$-azobisisobutyronitrile were carried out. The following reactivity ratios were found for the bulk copolymerization at $50^{\circ} \mathrm{C}$ for $1, r_{1}=0.004$, and for $2, r_{2}=4.4$. Radical reactivity indices and frontier electron densities for 1, 2, and 3-vinyl-1,4-butyrolactone were calculated.

KEY WORDS Poly(4-vinyl-1,4-butyrolactone-co-cyanoethylene) / Copolymerization / Radical Reactivity Ratio / Radical Reactivity Index / Frontier Electron Density /
\end{abstract}

The interest in the lactone function in the polymer chain originates from its ring-opening and ringclosing reactions. Some lactone-containing vinyl polymers such as poly(diketene-co-cyanoethylene), ${ }^{1}$ poly(diketene-co-chloroethylene), ${ }^{2}$ poly(diketene$\mathrm{co}$-styrene), ${ }^{3}$ poly(4-vinyl-1,4-butyrolactone-co4(5)-vinylimidazole), ${ }^{4}$ and poly(3-vinyl-1,4-butyrolactone-co-cyanoethylene), ${ }^{5}$ have already been investigated. The latter two copolymers have the lactone moieties in side chains. The last polymer was investigated with emphasis on its active- and selective-transport of metal ions. ${ }^{6}$ In the present paper, the radical copolymerization of 4-vinyl-1,4butyrolactone (1) and cyanoethylene (2) initiated by $2,2^{\prime}$-azobisisobutyronitrile is described. In addition, radical reactivity indices and frontier electron densities for 4-vinyl-1,4-butyrolactone (1), cyanoethylene (2), and 3-vinyl-1,4-butyrolactone are presented.

\section{EXPERIMENTAL}

\section{Materials}

4-Vinyl-1,4-butyrolactone (1) was synthesized from butadiene oxide and diethyl malonate ${ }^{7}$ bp $62-69^{\circ} \mathrm{C}[3 \mathrm{mmHg}(0.4 \mathrm{kPa})]$. Cyanoethylene (2) was purified in the usual manner.

\section{Polymerization}

Various amounts of $\mathbf{1}$ and $\mathbf{2}$ with various molar ratios were placed in an ampule with $0.5 \mathrm{wt} \%$ of $2,2^{\prime}$ - azobisisobutyronitrile and sealed under nitrogen atmosphere. The polymerization was carried out at $50^{\circ} \mathrm{C}$ under stirring. When the viscosity of the reaction mixture had slightly increased, the mixture was poured into diethyl ether and filtered. The residual precipitate was collected. No residual material was found in the filtrate.

\section{Polymer Composition}

The chemical composition of the copolymer was determined by elemental analyses of carbon and nitrogen.

\section{Viscosity Measurement}

The viscosity was measured with a $0.0004 \mathrm{~g} \mathrm{~cm}^{-3}$ solution of $\mathrm{N}, \mathrm{N}$-dimethylformamide at $25^{\circ} \mathrm{C}$.

\section{Spectroscopic Measurement}

Infrared spectra were recorded on a Hitachi EPIG2 spectrophotometer.

\section{Calculation}

All the calculations have been carried out by the use of the INDO MO method. ${ }^{8}$ The radical reactivity index (RRI), which is the measure of the reactivity of the monomer toward the radical, is defined by

$$
\mathrm{RRI}=\sum_{i}^{\text {occ }} \frac{\left(C_{r}^{(i)}\right)^{2}}{\lambda-\varepsilon_{i}}+\sum_{j}^{\text {uno }} \frac{\left(C_{r}^{(j)}\right)^{2}}{\varepsilon_{j}-\lambda}
$$

where $C_{r}^{(i)}, C_{r}^{(j)}$ are the coefficients of the $r$ th $2 p \Pi$ 
atomic orbital in the $i$ th and $j$ th MOs, respectively, whose energies are $\varepsilon_{i}$ and $\varepsilon_{j}$, respectively, and $\lambda$ denotes the energy of the singly-occupied MO of the attacking radical.

The frontier electron density $\left(f_{r}^{(R)}\right)$ is defined by

$$
f_{r}^{(\mathrm{R})}=\left(C_{r}^{(\mathrm{HO})}\right)^{2}+\left(C_{r}^{(\mathrm{LU})}\right)^{2}
$$

where $C_{r}^{(\mathrm{HO})}$ and $C_{r}^{(\mathrm{LU})}$ are the coefficients of the $r$ th $2 p \Pi$ atomic orbital in the highest-occupied and lowest-unoccupied MOs, respectively.

\section{RESULTS AND DISCUSSION}

The results of the copolymerization are shown in Table I. Molecular weights of the copolymers were

Table I. Result of the copolymerization of 4-vinyl-1,4-butyrolactone(1) and cyanoethylene $(2)^{a}$

\begin{tabular}{|c|c|c|c|c|c|c|c|c|c|c|}
\hline \multirow{2}{*}{$\begin{array}{c}\text { Expt } \\
\text { No. }\end{array}$} & \multicolumn{2}{|c|}{ Monomer } & \multirow{2}{*}{$\mathrm{AIBN} / \mathrm{mg}$} & \multirow{2}{*}{ Time $/ \mathrm{h}$} & \multirow{2}{*}{ Yield/g } & \multicolumn{2}{|c|}{ Elementary analysis $/ \%$} & \multicolumn{2}{|c|}{ Mol fraction of 1 in } & \multirow{2}{*}{$\eta_{\mathrm{sp}} / c$} \\
\hline & $1 / g$ & $2 / g$ & & & & $\mathrm{C}$ & $\mathrm{N}$ & Monomer & Polymer & \\
\hline 1 & 0.255 & 1.055 & 7.6 & 1.4 & 0.023 & 67.03 & 24.45 & 0.103 & 0.032 & 1.90 \\
\hline 2 & 0.382 & 0.916 & 6.9 & 2.5 & 0.016 & 66.56 & 23.31 & 0.165 & 0.052 & 1.00 \\
\hline 3 & 0.619 & 0.687 & 6.9 & 4.0 & 0.015 & 66.29 & 21.88 & 0.299 & 0.082 & 0.55 \\
\hline 4 & 0.766 & 0.544 & 6.6 & 17.9 & 0.058 & 66.86 & 19.77 & 0.400 & 0.136 & 0.40 \\
\hline 5 & 0.878 & 0.422 & 6.6 & 44.1 & 0.062 & 66.56 & 17.34 & 0.496 & 0.190 & 0.55 \\
\hline 6 & 0.982 & 0.309 & 6.8 & 44.2 & 0.051 & 65.33 & 16.52 & 0.600 & 0.212 & 0.40 \\
\hline 7 & 1.072 & 0.211 & 6.8 & 44.1 & 0.022 & 65.09 & 15.40 & 0.697 & 0.243 & 0.08 \\
\hline 8 & 1.183 & 0.111 & 6.9 & 44.5 & 0.019 & 64.16 & 12.02 & 0.835 & 0.350 & 0.10 \\
\hline 9 & 1.242 & 0.067 & 6.7 & 44.7 & 0.013 & 64.01 & 10.31 & 0.898 & 0.414 & 0.13 \\
\hline
\end{tabular}

a Polymerization temp, $50^{\circ} \mathrm{C}$. Reduced viscosity was measured at $c=0.0004 \mathrm{~g} \mathrm{~cm}^{-3}-\mathrm{DMF}, 25^{\circ} \mathrm{C}$.

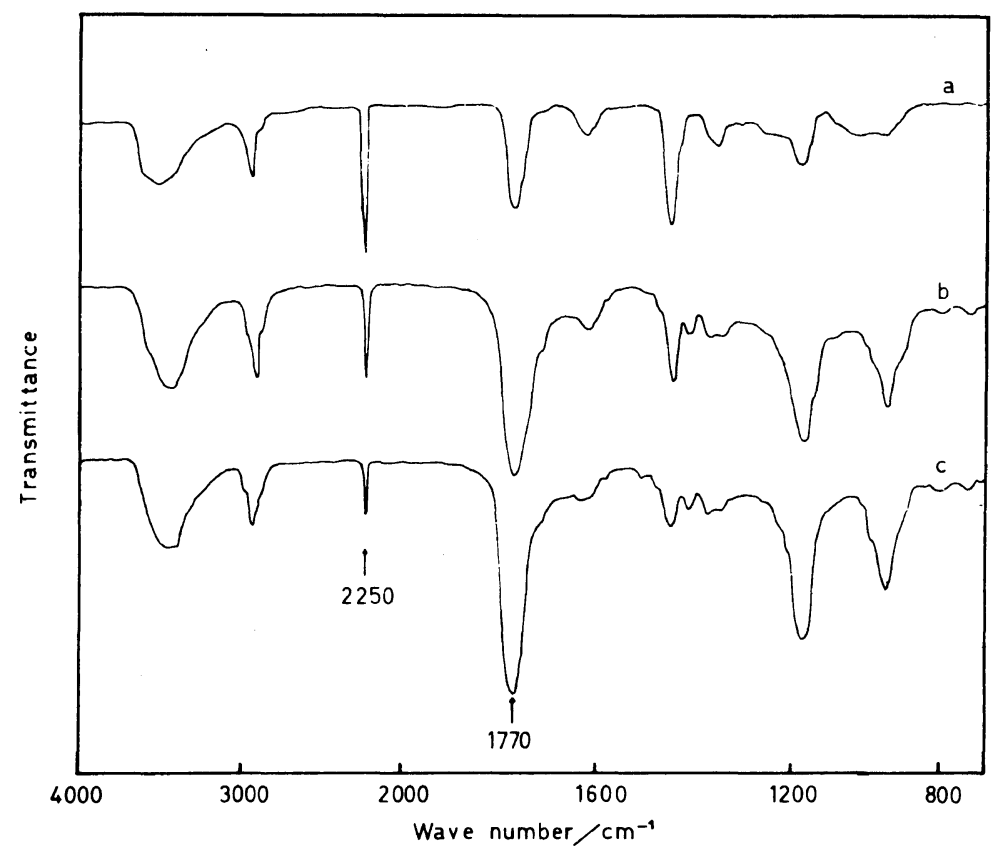

Figure 1. IR spectra of poly $(\mathbf{1}-c o-2) \mathrm{s}$ in $\mathrm{KBr}$ : a, 1:2=3.2:96.8; b, 1:2=24.3:75.7; c, 1:2=41.4:58.6; thickness, $0.24 \mathrm{~mm}(1 \mathrm{mg}$ polymer $/ 200 \mathrm{mg} \mathrm{KBr})$. 
not always high. The reduced viscosity decreased with increasing the content of 1 in the poly(1-co-2). The number-average molecular weight, $\bar{M}_{n}$, of the sample (Exptl. No. 7, which has the lowest reduced viscosity) was estimated to be $c a .1200$ for $\bar{M}_{n}$, adopting the molecular weight-viscosity relationship for polycyanoethylene. ${ }^{9}$ The homopolymerization of 1 had effectively stopped after 5 days.

Figure 1 shows the IR spectra of copolymers. The characteristic absorptions at $2250 \mathrm{~cm}^{-1}(-\mathrm{C} \equiv \mathrm{N})$ and $1770 \mathrm{~cm}^{-1}$ (lactone) are shown in Figure 1. These two characteristic absorptions were identical with those of poly(3-vinyl-1,4-butyrolactone-cocyanoethylene). ${ }^{5}$

In Figure 2, these absorptions are shown quantitatively.

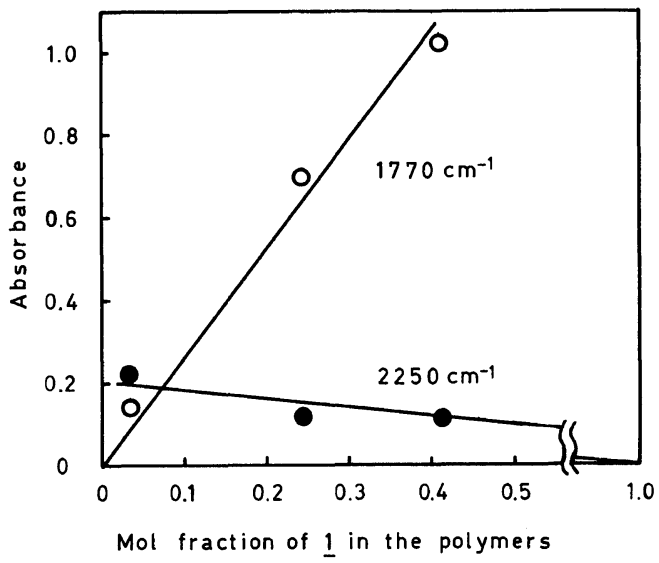

Figure 2. Absorbances at $1770 \mathrm{~cm}^{-1}$ and $2250 \mathrm{~cm}^{-1}$ of poly(1-co-2)s against their composition.

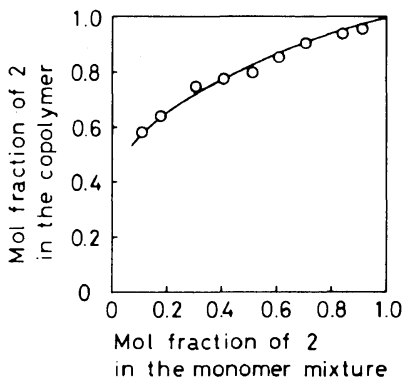

Figure 3. Polymer vs. monomer composition in the copolymerization of 4-vinyl-1,4-butyrolactone (1) and cyanoethylene (2); polymerization temp, $50^{\circ} \mathrm{C}$; initiator, $2,2^{\prime}$-azobisisobutyronitrile.

Figure 3 shows the copolymer composition dia-

Table II. Radical reactivity indices (RRI) and frontier electron densities $\left(f r^{(\mathrm{R})}\right)$ for 1,2 , and 3

\begin{tabular}{ccc}
\hline Position & $\mathrm{RRI}^{\mathrm{a}}$ & $f r^{(\mathrm{R})}$ \\
\hline $\mathrm{a}$ & 2.51 & 0.442 \\
$\mathrm{~b}$ & 2.77 & 0.597 \\
$\mathrm{c}$ & 2.50 & 0.525 \\
$\mathrm{~d}$ & 2.82 & 0.786 \\
$\mathrm{e}$ & 2.59 & 0.360 \\
$\mathrm{f}$ & 2.78 & 0.458 \\
\hline
\end{tabular}

a RRI was calculated, taking the value $\lambda=-0.15$ a.u.

$1:$<smiles>[2H]C=CC1CCC(=O)O1</smiles>

$2:$<smiles>N#C[C]=C[Ge]</smiles>

3<smiles>O=C1CC(C=CF)CO1</smiles>

gram. The radical reactivity ratios were determined to be $r_{1}=0.004$ and $r_{2}=4.4$ by the Kelen-Tüdõs method. ${ }^{10}$ The radical reactivity ratio of 1 was lower than that of 3-vinyl-1,4-butyrolactone (3) in the copolymerization with 2 . In general, the degree of polymerization of poly(1-co-2) was lower than that of poly(3-co-2). ${ }^{5}$

In Table II, radical reactivity indices (RRI) and frontier electron densities $\left(f_{r}^{(\mathbf{R})}\right)$ are shown; here the oribital energy of the radical, $\lambda$, which attacks the monomer, is assumed to be -0.15 a.u. Even if the orbital energy of the attacking radical was assumed to be $-0.05,-0.10,-0.20$, or -0.25 a.u., these trends were similar to that in Table II. RRI indicates that the reacting position of the monomer toward the growing chain radical is mostly often at the $d$-carbon in 2 and at the $b$-carbon in 1. Accordingly, the polymer structure is to be a head-to-tail one and the growing chain terminals are to be

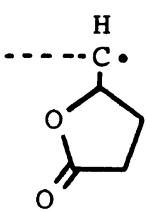

4

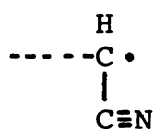

5 
The growing chain terminal structure, $\mathbf{4}$, is readily converted into allylic radical by losing its 4-hydrogen; the growing chains, $\mathbf{4}$ and $\mathbf{5}$, may also subtract the 4-hydrogen of another molecule of $\mathbf{1}$. Accordingly, the molecular weight of the copolymer decreased with the feed of $\mathbf{1}$.

When this copolymer was immersed in $1 \mathrm{~mol} \mathrm{dm}^{-3}$ alkaline solution, it dissolved. Acidification of the solution then caused precipitates to form. Thus, the ring-opening and the ring-closing reactions of the lactone moiety in the polymer take place with alkali and acid in analogy with the processes involving poly(3-co-2). ${ }^{5}$.

Acknowledgment. Financial aid by the Ministry of Education is acknowledged. The authors are grateful to the Data Processing Center of Kyoto University for its generous permission to use the FACOM M 190 Computer.

\section{APPENDIX}

From the MO perturbation theory, ${ }^{11}$ the stabilization of the composite reacting system to the delocalization of electrons between the radical, R, and the closed-shell monomer, $\mathrm{M}$, is given by

$$
\begin{aligned}
D & \simeq 2\left\{\sum_{i}^{\text {occ uno }} \sum_{j} \frac{\left(\Sigma_{r} C_{r}^{(i)} C_{r^{\prime}}^{(l)} \gamma_{r r^{\prime}}^{(i)}\right)^{2}}{I_{\mathrm{M} i}^{(\mathrm{R})}-E_{\mathrm{R} l}^{(\mathrm{M}-i)}}\right. \\
& \left.+\sum_{k}^{\text {occ uno }} \sum_{j} \frac{\left(\Sigma_{r} C_{r}^{(j)} C_{r^{\prime}}^{(k)} \gamma_{r r^{\prime}}^{(k)}\right)^{2}}{I_{\mathrm{R} k}^{(\mathrm{M})}-E_{\mathrm{M} j}^{(\mathrm{R}-k)}}\right\} \\
& +\left\{\sum_{i}^{\text {occ }} \frac{\left(\Sigma_{r} C_{r}^{(i)} C_{r^{\prime}}^{(o)} \gamma_{r r^{\prime}}^{(i)}\right)^{2}}{I_{\mathrm{M} i}^{(\mathrm{R})}-E_{\mathrm{R} o}^{(\mathrm{M}-i)}}+\sum_{j}^{\text {uno }} \frac{\left(\Sigma_{r} C_{r}^{(j)} C_{r^{\prime}}^{(o)} \gamma_{r^{\prime}}^{(o)}\right)^{2}}{I_{\mathrm{R} o}^{(\mathrm{M})}-E_{\mathrm{M} j}^{(\mathrm{R}-o)}}\right\}
\end{aligned}
$$

where $C_{r}^{(i)}$ and $C_{r}^{(j)}$ are the coefficients of the $\mathrm{AO} \chi_{r}$ in the occupied MO $\phi_{i}$ and the unoccupied MO $\phi_{j}$ of the monomer, respectively; $C_{r^{\prime}}^{(k)}, C_{r^{\prime}}^{(l)}$, and $C_{r^{\prime}}^{(o)}$ are the coefficients of the $\mathrm{AO} \chi_{r^{\prime}}$ in the occupied $\mathrm{MO} \psi_{k^{\prime}}$, the unoccupied $\mathrm{MO} \psi_{l}$, and the singly-occupied $\mathrm{MO} \psi_{0}$ of the the radical $\mathrm{R}$, respectively; $\phi_{i}=\sum_{r} C_{r}^{(i)} \chi_{r}$, $\psi_{l}=C_{r^{\prime}}^{(l)} \chi_{r^{\prime}}$ etc.

The integral, $\gamma_{r r^{\prime}}$, represents the interaction between the reaction centers $r$ and $r^{\prime}$ through the overlap between the AOs $\chi_{r}$ and $\chi_{r} ; \gamma_{r r^{\prime}}=\int \chi_{r} h \chi_{r^{\prime}} \mathrm{d} \tau$.

$I_{\mathrm{M} i}^{(\mathrm{R})}$ is the ionization potential of the MO $\phi_{i}$ of the monomer $\mathrm{M}$ in the neutral field of the attacking radical $\mathrm{R}$, and $E_{\mathrm{R} l}^{(\mathrm{M}-i)}$ is the electron affinity of the
MO $\psi_{l}$ of the radical $\mathbf{R}$ under the influence of the cationic species $(\mathrm{M}-i)$ generated by the removal of an electron from the MO $\phi_{i}$ of M. The summation $\sum^{\text {occ }}$ and $\sum$ cover all the occupied and unoccupied MOs, respectively.

If we assume that the singly occupied MO of the radical, $\psi_{o}$, is localized at the radical center, as is often the case, the first and second terms in eq 3 vanish. Because the interaction integral, $\gamma_{r r}$, between the reaction centers of the radical and the monomer is approximately common to all the MO combinations, the radical reactivity index (RRI), which is the measure of the reactivity of the monomer toward the radical, is defined by eq 1 . Using the selfconsistent field MO energies, the denominator of eq 3 is represented by

$$
I_{\mathrm{M}_{i}}^{(\mathrm{R})}-E_{\mathrm{R} l}^{(\mathrm{M}-i)} \simeq \varepsilon_{\mathrm{M} i}-\varepsilon_{\mathrm{R} l}+(i i \mid l l)
$$

where $(i i \mid l l)$ is the coulombic repulsion integral between the electrons in the MO $\phi_{i}$ and the MO $\psi_{l}$. The coulombic repulsion for the ordinary reaction system is about 0.1 a.u. In the present paper, the repulsion term was disregarded because the attacking radical has not been identified.

\section{REFERENCES}

1. G. A. Gabrielyan and Z. A. Rogovin, Khim. Volokna, 5, 2 (1963)

2. K. Matsuoka, K. Takemoto, and M. Imoto, Kogyo Kagaku Zasshi, 68, 1135 (1965).

3. T. M. Frunze, M. A. Surikova, V. V. Kurashev, and L. I. Komarova, Vysokomol. Soedin., Ser. A, 12, 460 (1970).

4. T. Shimidzu, A. Furuta, T. Watanabe, and S. Kato, Makromol. Chem., 175, 119 (1974).

5. T. Shimidzu, M. Yoshikawa, H. Chiba, and A. Murakami, Makromol. Chem., 178, 1923 (1977).

6. T. Shimidzu, M. Yoshikawa, M. Hasegawa, and H. Chiba, Kobunshi Ronbunshu, 34, 753 (1977).

7. R. R. Russell and C. A. VanderWerf, J. Am. Chem. Soc., 69, 11 (1947).

8. J. A. Pople and D. L. Beveridge, "Approximate Molecular Orbital Theory", McGraw-Hill, New York, N.Y., 1970.

9. P. F. Onyon, J. Polym. Sci., 22, 13 (1965).

10. T. Kelen and F. Tüdõs, J. Macromol. Sci.-Chem., A9, 1 (1975)

11. K. Fukui, "Molecular Orbitals in Chemistry, Physics, and Biology," P. O. Löwdin and B. Pullman, Ed., Academic Press, New York, N.Y., 1964; K. Fukui, "Theory of Orientation and Stereoselection," 


\section{Poly(4-vinyl-1,4-butyrolactone-co-cyanoethylene)}

Springer-Verlag, Berlin, 1970; H. Fujimoto and K. Fukui, "Advances in Quantum Chemistry," Vol. 6, P.
O. Löwdin Ed., Academic Press, New York, N.Y., 1972. 